\title{
Gradhiva
}

Revue d'anthropologie et d'histoire des arts

1 | 2005

Haïti et l'anthropologie

\section{Madison Smartt Bell, Le Soulèvement des âmes et Le Maître des carrefours}

Arles, Actes Sud, 1995, 620 p. ; Arles, Actes Sud, 2004, 950 p., trad. de

l'américain par Pierre Girard

\section{Nicolas Menut}

\section{CpenEdition}

\section{Journals}

\section{Édition électronique}

URL : http://journals.openedition.org/gradhiva/405

DOI : $10.4000 /$ gradhiva.405

ISSN : 1760-849X

Éditeur

Musée du quai Branly Jacques Chirac

\section{Édition imprimée}

Date de publication : 1 mai 2005

Pagination : 263-265

ISBN : 2-915133-08-5

ISSN : 0764-8928

Référence électronique

Nicolas Menut, " Madison Smartt Bell, Le Soulèvement des âmes et Le Maître des carrefours », Gradhiva

[En ligne], 1 | 2005, mis en ligne le 10 décembre 2008, consulté le 21 septembre 2020. URL : http://

journals.openedition.org/gradhiva/405; DOI : https://doi.org/10.4000/gradhiva.405

Ce document a été généré automatiquement le 21 septembre 2020.

(c) musée du quai Branly 


\section{Madison Smartt Bell, Le Soulèvement des âmes et Le Maître des carrefours}

Arles, Actes Sud, 1995, 620 p. ; Arles, Actes Sud, 2004, 950 p., trad. de l'américain par Pierre Girard

Nicolas Menut

\section{RÉFÉRENCE}

Madison Smartt Bell, Le Soulèvement des âmes, Arles, Actes Sud, 1995, 620 p., trad. de l'américain par Pierre Girard

Madison Smartt Bell, Le Maître des carrefours, Arles, Actes Sud, 2004, 950 p., trad. de l'américain par Pierre Girard

1 Il est des entreprises littéraires risquées et déraisonnables. La biographie romancée de Toussaint-Louverture par l'écrivain américain Madison Smartt Bell en est incontestablement un parfait exemple.

2 Madison Smartt Bell publie son premier roman en 1983 sous le titre The Washington Square Ensemble (Viking Press) et se fait connaître du grand public avec Save me, Joe Louis $^{1}$ et Ten Indians ${ }^{2}$. La célèbre et influente revue Granta le sélectionne dans la liste des meilleurs écrivains américains de moins de 40 ans en 1996, un an après la publication de All Soul's Rising (Le Soulèvement des âmes), finaliste du National Book Award en 1995 et du Pen/Faulkner Award en 1996.

3 Les révolutions ont souvent engendré des œuvres littéraires hors normes, épaisses et labyrinthiques: les écrits de Victor Serge ${ }^{3}$ et John Reed ${ }^{4}$ en sont deux exemples incontournables. Cependant le travail entrepris par Smartt Bell semble encore repousser les limites du genre. Victor Serge et John Reed avaient été les témoins de leur époque et en devinrent, dans une certaine mesure, les historiens. Il n'en va pas de même pour l'auteur du Soulèvement des âmes, qui ne put effectuer son premier séjour en Haïti qu'après la publication de l'ouvrage. Il aura mis dix années à écrire les deux 
premiers volumes d'une biographie qu'il annonce comme un triptyque (le dernier volume étant en cours de rédaction) et qui devrait comporter quelque 3000 pages...

Dans un entretien accordé à l'excellent magazine américain Bomb $b^{5}$, il revient sur la genèse de son projet : « When researching Santeria for the Washington Square Ensemble I read a lot about Vodou, which was then more popular with anthropologists so there was more to read, and I became extremely interested. [...] I came across the Haitian Revolution under the rubric of terrorism and got interested in the career of Toussaint. I read a short biography called Citizen Toussaint by Ralph Korngold and saw in his personal story a novel more or less already written. »

Vodou, terrorisme, révolution... le cocktail ainsi présenté aurait toutes les raisons d'être indigeste pour l'historien sceptique, qui rangerait d'office cet ouvrage entre L'île magique de William Seabrook et $L a$ Tragédie du roi Christophe d'Aimé Césaire. Cependant l'accueil réservé par plusieurs intellectuels haïtiens (dont Michel-Rolph Trouillot et Patrick Delatour) au Soulèvement des âmes prouve le sérieux et la rigueur du travail de Smart Bell.

6 Le récit s'appuie sur de solides recherches archivistiques. Il n'est, pour s'en convaincre, qu'à lire les notes et suppléments qui accom-pagnent les deux volumes: chronologie historique très complète, glossaire, reproductions des lettres et documents originaux, cartes, sans omettre une surprenante classification des races dans la colonie de SaintDomingue, extraite de Description topographique, physique, civile, politique et historique de la partie française de l'isle de Saint-Domingue par Médéric-Louis-Elie Moreau de Saint-Méry en 1797.

7 Madison Smartt Bell n'est évidemment pas le premier à s'intéresser à la figure de Toussaint Louverture. Victor Schoelcher lui consacra une biographie ${ }^{6}$, avant que Pierre Pluchon ne publie en 1989 l'ouvrage de référence sur le sujet ${ }^{7}$. Toussaint Louverture, ancien esclave affranchi, y est décrit comme le maître d'œuvre de l'abolition de l'esclavage à Saint-Domingue, figure secrète et charismatique de la Révolution, mais également personnage ambigu, catholique fervent (donc fort éloigné de l'esprit des Lumières), qui n'aura de cesse de vouloir reconstituer la structure coloniale à la seule faveur des Noirs.

8 L'écrivain américain en propose un portrait complémentaire, bien moins sombre que celui dressé par Pierre Pluchon. Il passe quasiment sous silence le parcours de Toussaint Louverture durant les trente premières années de sa vie qui, si l'on en croit Pierre Pluchon, furent des années de formation mouvementées, où le futur général n'avait pas forcément le meilleur rôle... Smartt Bell semble également oublier que, affranchi depuis peu, celui que l'on connaissait alors sous le nom de Toussaint Bréda était alors propriétaire d'une plantation modeste et commandait à quelques esclaves.

9 À l'exception de ces quelques remarques soulignant d'étranges omissions, il convient de préciser la richesse de cette biographie: richesse sur le plan de la technique littéraire et du style, mais aussi richesse des références historiques et culturelles. La structure même du roman (chaque chapitre est conçu sous forme de monologues intérieurs ou de récits à la troisième personne) permet une multitude d'angles de vues, d'opinions, voire de descriptions d'un même fait ou d'un même personnage. Smartt Bell ne donne pas seulement la parole aux esclaves ou aux futurs leaders noirs, car mulâtres, planteurs créoles et soldats français (royalistes et républicains) y 
apparaissent également, élargissant ainsi les perspectives et illustrant souvent avec force détails la complexité des relations sociales et raciales sur l'île.

Biographie romancée donc, mais aussi véritable précis de géographie haïtienne où l'auteur inclut la trame de son récit dans un paysage complexe où abondent les détails. On se souviendra que William Seabrook dans L'île magique avait déjà fait de même, s'attardant à la minutieuse description des chemins et ravines parcourus, comme si se dessinait dans cet enchevêtrement végétal, parfois idyllique mais aussi très souvent austère, une allégorie de la culture haïtienne. Et cette profusion est aussi l'un des défauts de la biographie. À vouloir ainsi jouer d'excès, on a parfois l'impression que Smartt Bell semble prendre un malin plaisir à tirer à la ligne, promenant son lecteur sur des chemins de traverses tantôt desséchés, tantôt boueux, où il est parfois difficile de ne pas perdre patience.

11 Excès que l'on retrouve également dans le réalisme à outrance accordé aux scènes de violence. Cependant, si certains passages du premier volume de la trilogie sont difficilement soutenables, ils n'apparaissent pas pour autant gratuits, nous rappelant que les révolutions sont rarement de velours. Ce réalisme cru, parfois à la frontière $\mathrm{du}$ sordide, s'offre également comme un miroir d'une société haïtienne moderne qui n'en finit pas de panser ses plaies pour mieux les rouvrir.

Smartt Bell insiste également sur l'importance de la religion vodou, la jugeant intrinsèquement liée à la structure des orga- nisations révolutionnaires :

«... the more you read Haitian history, the more you see how voodoo played a part in the rebellion because the structure of that religious community was cellular, the way that revolutionary organizations are cellular $»^{8}$.

13 Une telle assertion implique, à tout le moins, une lecture fort subjective de la révolution haïtienne mais illustre la manière (voire l'artifice) dont l'auteur parvient à lier politique et religion. Pour autant, il ne faut pas s'attendre à voir ici défiler tous les clichés usés de la "mythologie » vodou'. Le roman n'en est certes pas exempt, mais l'écrivain a su trouver un juste équilibre entre la liberté accordée par la forme romanesque et un réel souci de vraisemblance. Le personnage de Riau, l'une des figures centrales de la fresque, en est le parfait exemple, symbole d'un syncrétisme douloureux entre des croyances africaines ancestrales et l'obligation d'assimiler un code de conduite régi par des normes européennes. Tantôt chevauché par Kalfou ou OgûnFerraille, tantôt capitaine au sein des troupes de Toussaint Louverture, l'ancien esclave Riau tente laborieusement de conjuguer ces contradictions à la recherche d'un équilibre précaire, d'une identité... Smartt Bell évite presque toujours les écueils du pittoresque pour évoquer le rituel vodou, et il est manifeste que l'auteur a lu et assimilé, au cours de ses nombreuses recherches, la littérature sur le sujet.

14 Il convient dorénavant d'attendre le troisième et dernier volet de cette trilogie, qui devrait notamment évoquer la prise de pouvoir de Toussaint Louverture, sa gouvernance puis sa chute. Et si, comme nous l'espérons, ce volume est à l'égal des deux premiers, il sera alors d'actualité d'affirmer que cette biographie romancée prouve encore une fois, s'il en était besoin, toute l'originalité et la vitalité de la littérature nord-américaine qui n'a guère d'équivalent aujourd'hui. 


\section{NOTES}

1. 1994, publié en français sous le même titre aux éditions Actes Sud (« Babel » 227).

2. Dix Indiens, Arles, Actes Sud, 1999.

3. Cf. la réédition de Mémoires d'un révolutionnaire et autres écrits politiques 1908-1947, Paris, Robert Laffont (« Bouquins »), 2001.

4. Le Mexique insurgé, Paris, Éd. du Seuil, 1998 et Dix jours qui ébranlèrent le monde, Paris, Éd. du Seuil, 1996.

5. L'intégralité de cet entretien peut être lu sur le site du magazine : http://www.bombsite.com/

6. Vie de Toussaint Louverture, Paris, Karthala, 1982.

7. Toussaint Louverture, Paris, Fayard, 1989.

8. Extrait d'un entretien avec Justin Cronin in Four Quarters, Spring 1995, LaSalle University, Philadelphia

9. Les amateurs du genre ne manqueront pas dans ce cas la réédition dvd de Vaudou du cinéaste Jacques Tourneur qui joue, quant à lui, sur un registre clairement référentiel, voire kitsch. Coffret Jacques Tourneur, La Féline, Vaudou, L'Homme Léopard. Éditions Montparnasse, 2003.

\section{AUTEUR}

\section{NICOLAS MENUT}

nicolas.menut@quaibranly.fr 